\title{
(2) OPEN ACCESS \\ Time to desaturation in preterm infants undergoing endotracheal intubation
}

\author{
Radhika Kothari (D) ,' Kate Alison Hodgson (D) , 1,2,3 Peter G Davis (D) , 1,2,4,5 \\ Marta Thio, ${ }^{1,2,3,4,5}$ Brett James Manley, ${ }^{1,2,4,5}$ Eoin $0^{\prime}$ Currain (D) 1,3,6,7
}

\begin{abstract}
${ }^{1}$ Newborn Research Centre, The Royal Women's Hospital, Parkville, Victoria, Australia ${ }^{2}$ Department of Obstetrics and Gynaecology, The University of Melbourne, Melbourne, Victoria, Australia

${ }^{3}$ Paediatric Infant Perinata Emergency Retrieval, The Royal Children's Hospital, Parkville,

Victoria, Australia

${ }^{4}$ Murdoch Children's Research Institute, Melbourne, Victoria, Australia

${ }^{5}$ University of Melbourne, Melbourne, Victoria, Australia ${ }^{6}$ University College DublinNational University of Ireland, Dublin, Ireland

${ }^{7}$ The National Maternity Hospital, Holles St, Dublin, Ireland
\end{abstract}

Correspondence to Dr Radhika Kothari, Neontalogy, Royal Women's Hospital, Parkville VIC 3052, Australia; kothari.radhika@icloud.com

Received 2 October 2020 Revised 13 March 2021 Accepted 23 March 2021 Published Online First 30 April 2021
ABSTRACT
Background

(neonatal endotracheal intubation is often associated with physiological instability. The Neonatal Resuscitation Program recommends a time-based limit (30 s) for intubation attempts in the delivery room, but there are limited physiological data to support recommendations in the neonatal intensive care unit (NICU). We aimed to determine the time to desaturation after ceasing spontaneous or assisted breathing in preterm infants undergoing elective endotracheal intubation in the NICU.

Methods Observational study at The Royal Women's Hospital, Melbourne. A secondary analysis was performed of video recordings of neonates $\leq 32$ weeks' postmenstrual age undergoing elective intubation. Infants received premedication including atropine, a sedative and muscle relaxant. Apnoeic oxygenation time (AOT) was defined as the time from the last positive pressure or spontaneous breath until desaturation $\mathrm{SpO}_{2}$ $<90 \%$ ).

Results Seventy-eight infants were included. The median (IQR) gestational age at birth was 27 (26-29) weeks and birth weight $946(773-1216) \mathrm{g}$. All but five neonates desaturated to $\mathrm{SpO}_{2}<90 \%(73 / 78,94 \%)$. The median (IQR) AOT was 22 (14-32) s. The median (IQR) time from ceasing positive pressure ventilation to desaturation $<80 \%$ was $35(24-44) \mathrm{s}$ and to desaturation $<60 \%$ was 56 (42-68) s. No episodes of bradycardia were seen.

Conclusions This is the first study to report AOT in preterm infants. During intubation of preterm infants in the NICU, desaturation occurs quickly after cessation of positive pressure ventilation. These data are important for the development of clinical guidelines for neonatal intubation.

Trial registration number ACTRN12614000709640

\section{BACKGROUND}

Neonatal endotracheal intubation is frequently associated with physiological instability. ${ }^{1}$ Adverse events, including bradycardia, fluctuations in blood pressure and severe desaturation, commonly occur during intubation attempts. ${ }^{1-4}$ Half of attempted intubations of preterm infants are associated with a fall in peripheral oxygen saturation $\left(\mathrm{SpO}_{2}\right)$ levels of $\geq 20 \%$. $^{25}$ Adverse events often result in the termination of the intubation attempt, and are the most common reason for an unsuccessful intubation. ${ }^{6}$

The duration of intubation attempts varies with the experience of the operator and may be longer than the maximum suggested in international guidelines. ${ }^{7}$ In the delivery room (DR), the Neonatal

\section{What is already known on this topic?}

- Neonatal intubation is often associated with physiological instability, and the duration of attempts may be longer than the maximum suggested in international guidelines.

- The Neonatal Resuscitation Program recommends a time-based limit (30s) for intubation attempts in the delivery room; however, there are limited physiological data to support recommendations after birth in the neonatal intensive care unit (NICU).

- Apnoeic oxygenation time (AOT) is the time from the last positive pressure or spontaneous breath until desaturation $\left(\mathrm{SpO}_{2}<90 \%\right)$.

\section{What this study adds?}

- This is the first study to report the time to desaturation after ceasing positive pressure or spontaneous breaths in preterm neonates undergoing intubation in the NICU.

- AOT is substantially shorter in preterm infants compared with paediatric patients, and desaturation occurs quickly after ceasing assisted or spontaneous breaths.

Resuscitation Program (seventh edition, American Academy of Pediatrics, 2016) recommends that intubation attempts in neonates should be limited to $30 \mathrm{~s}$ or stopped when there is physiological instability (bradycardia, oxygen desaturation). However, there are no specific recommended heart rate (HR) or oxygen saturation $\left(\mathrm{SpO}_{2}\right)$ thresholds at which the intubation attempt should be stopped, and there are limited physiological data to support time-based recommendations in the neonatal intensive care unit (NICU). ${ }^{8}$

Apnoeic oxygenation time (AOT) has been defined as the time from the last positive pressure or spontaneous breath until desaturation $\left(\mathrm{SpO}_{2}\right.$ $<90 \%)$. Desaturation occurs more rapidly in apnoeic children than in apnoeic adults receiving general anaesthesia. ${ }^{8}$ The increased instability of apnoeic children may be explained by a smaller functional residual capacity, greater metabolic demand and greater tendency for airway collapse compared with apnoeic adults. ${ }^{9} 10$ Kinouchi et $a l^{11}$ studied the AOT in children aged 1 month to 12 years and concluded that $\mathrm{SpO}_{2}$ decreases to 
$<95 \%$ more quickly in younger children compared with older children. Patel et al $^{12}$ measured the time until desaturation $\left(\mathrm{SpO}_{2}\right.$ $<90 \%$ ) during apnoea in healthy children (2 days to 10 years) and showed that $\mathrm{SpO}_{2}$ declines more rapidly in infants and children $\left(\mathrm{SpO}_{2}<90 \%\right.$ in $\left.94-214 \mathrm{~s}\right)$ than in adolescents $\left(\mathrm{SpO}_{2}<90 \%\right.$ in $364 \mathrm{~s})$.

These observations suggest that the desirable duration for endotracheal intubation of newborn infants may be even shorter. To date, AOT has not been reported in preterm infants. The aim of this study was to describe the AOT of preterm infants undergoing elective endotracheal intubation in the NICU.

\section{METHODS}

This was a secondary analysis of a randomised trial comparing two different facemask sizes used to deliver positive pressure ventilation (PPV) to preterm infants prior to undergoing elective endotracheal intubation at The Royal Women's Hospital (RWH), Melbourne, Australia. ${ }^{13}$ As part of this randomised trial, video recordings of endotracheal intubations were collected. RWH is a tertiary perinatal centre with $>7500$ births per year. Eligible infants were those $\leq 32$ weeks' corrected gestation who required PPV before elective intubation in the NICU. Elective intubations were defined as those in which infants received sedation and muscle relaxation prior to the procedure. Infants with known facial or airway anomalies were excluded.

Infants were first administered continuous positive airway pressure via a facemask and a Neopuff Infant Resuscitator T-piece (Fisher \& Paykel, Auckland, New Zealand). Any increase in positive end-expiratory pressure (PEEP) during PPV prior to intubation was at clinician discretion. Preoxygenation was not provided routinely, but infants did receive additional oxygen if hypoxaemic, to the unit-specific target $\left(\mathrm{SpO}_{2} 91 \%-95 \%\right)$. All infants received sedation (fentanyl, $5 \mu \mathrm{g} / \mathrm{kg}$ ) and muscle relaxation (suxamethonium, $2 \mathrm{mg} / \mathrm{kg}$ ), along with atropine $(20 \mu \mathrm{g} /$ $\mathrm{kg})$. Facemask ventilation was then administered using the Neopuff Infant Resuscitator T-piece. Intubation was performed by paediatric doctors (residents, registrars, fellows or consultants), supervised by a neonatal fellow or consultant. All intubations were performed using sterile, single-use, uniform internal diameter, plastic endotracheal tubes (Mallinckrodt Medical, Athlone, Ireland) under direct laryngoscopy. Only the first intubation attempt of each infant was included in the analysis and each infant was included only once.

Continuous $\mathrm{SpO}_{2}$ and $\mathrm{HR}$ data were recorded during the intubation attempt using a pulse oximeter (Masimo Radical 7; Masimo Corporation, Irvine, California, USA) and measurements of $\mathrm{SpO}_{2}$ and $\mathrm{HR}$ were recorded every $2 \mathrm{~s}$ during the apnoeic period. Infants were excluded if continuous pulse oximetry data (showing both $\mathrm{HR}$ and $\mathrm{SpO}_{2}$ ) were not available for the entire period of apnoea. Video recordings were made of all episodes of facemask PPV using an angled webcam (Logitech) and continued until successful endotracheal intubation.

\section{Outcomes}

The primary outcome measure was AOT, defined as the time from the last positive pressure inflation or spontaneous breath until desaturation $\left(\mathrm{SpO}_{2}<90 \%\right)$. This outcome was chosen to be consistent with other studies. ${ }^{12} 1415$ Secondary outcomes included patient instability during the intubation attempt, as measured by the infant's lowest $\mathrm{HR}$, the lowest $\mathrm{SpO}_{2}$ during apnoea, desaturations $\left(\mathrm{SpO}_{2}<80 \%\right.$ and $\left.\mathrm{SpO}_{2}<70 \%\right)$ and severe hypoxaemia $\left(\mathrm{SpO}_{2}<60 \%\right)$.

\section{Data collection}

All video recordings were reviewed by a study investigator (RK) and the AOT was determined. A sample of 20 videos was independently reviewed by three study investigators (RK, EOC, $\mathrm{KAH})$ to ensure consistency. Inconsistencies were resolved by group review. The duration of an intubation attempt was defined as the time from the last positive pressure inflation or last spontaneous breath until PPV recommenced (either via a T-piece with face mask or an endotracheal tube). Demographic data collected included gestational age (GA), birth weight, age and weight at intubation. Data were recorded on a paper-based Case Record Form and then entered into an electronic database $\left(\right.$ REDCap $\left.{ }^{16}\right)$.

\section{Sample size and statistical analysis}

This was a convenience sample of videos recorded in a randomised trial. Continuous data at each time point were analysed as mean (SD) if normally distributed, otherwise as median (IQR). $\mathrm{SpO}_{2}$ (median, IQR) was graphically represented. Kaplan-Meier survival curves were produced to determine the probability of desaturation.

\section{RESULTS}

Videos of endotracheal intubation were available from 119 patients in the original randomised controlled trial. Forty-one infants were excluded because continuous $\mathrm{SpO}_{2}$ data for the apnoeic period were not available. The remaining 78 infants were included in the analysis (figure 1). Their median (IQR) GA at birth was 27 (26-29) weeks and birth weight 946 (7731216) g. Median (IQR) age at intubation was 36 (10-312) hours. Baseline infant characteristics are presented in table 1.

Residents/registrars (paediatric trainees) performed 62/78 (79\%) intubation attempts, fellows (advanced neonatal trainees)

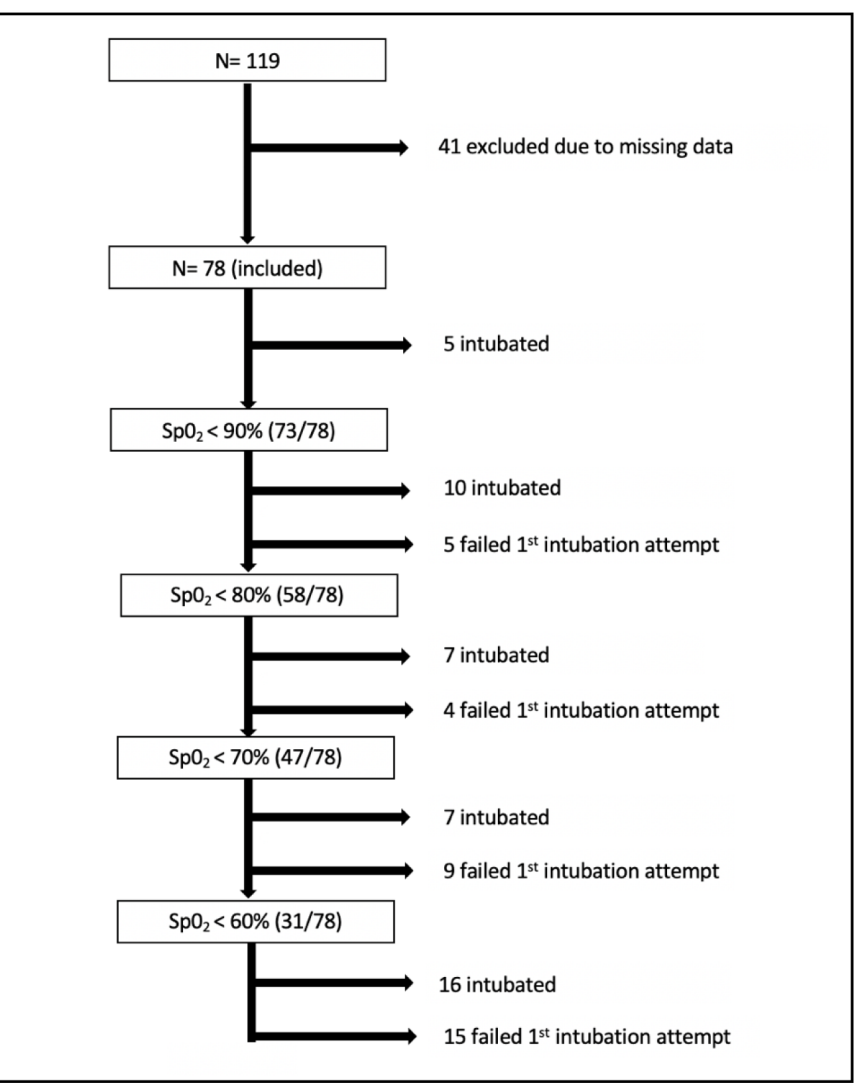

Figure 1 Flow diagram of included patients. 
Table 1 Baseline characteristics

\begin{tabular}{ll}
\hline & $\mathrm{N}=78$ \\
\hline Birth weight (g) & $946(773-1216)$ \\
\hline Gestational age (weeks) & $27(26-29)$ \\
\hline Age at intubation (hours) & $36(10-312)$ \\
Weight when studied (g) & $980(846-1263)$ \\
\hline Post-menstrual age (weeks) & $28(27-30)$ \\
Male, no (\%) & $45(58)$ \\
Apgar score at 1 min & $5(3-7)$ \\
\hline
\end{tabular}

Values are median, intraquartile range (IQR) or number $(\%)$.

14/78 (18\%) and consultants 2/78 (3\%). Practitioners with $<1$ year experience performed 52/78 (67\%) of attempts. The most common reasons for intubation were respiratory failure $(58 / 78$ (74\%) infants), apnoea (13/78 (17\%)) and elective endotracheal tube change $(4 / 78(5 \%))$. All infants received PPV following muscle relaxation; therefore, the last positive pressure inflation marked the beginning of the apnoeic period in all infants. The maximum fraction of inspired oxygen $\left(\mathrm{FiO}_{2}\right)$ before intubation was median (IQR) $0.81(0.60-1.00)$ and maximum PEEP delivered via facemask was $6(5-7) \mathrm{cm}$ of water $\left(\mathrm{cm} \mathrm{H}_{2} \mathrm{O}\right)$. All infants were intubated orally. All but five infants $(73 / 78,94 \%)$ desaturated to $\mathrm{SpO}_{2}<90 \%$ during the apnoeic period (figure 1 ). The median (IQR) AOT (time to $\mathrm{SpO}_{2}<90 \%$ ) for these 73 infants was 22 (14-32) s. The median (IQR) time to $\mathrm{SpO}_{2}<80 \%(58 / 78$ infants) was $35(24-44)$ s, to $\mathrm{SpO}_{2}<70 \%$ (47/78 infants) was 46 (32-56) s and to $\mathrm{SpO}_{2}<60 \%$ (31/78 infants) was 56 (42-68) s (figure 2). No bradycardia ( $\mathrm{HR}<100 \mathrm{bpm}$ ) was observed in any infant. The median (IQR) lowest $\mathrm{SpO}_{2}$ during the apnoeic period was $84 \%$ (70\%-95\%).

Figure 3 shows the median and IQR of the peripheral oxygen saturation at each second after ceasing PPV.

\section{DISCUSSION}

To our knowledge, this is the first study to report AOT in preterm infants and to characterise the changes in $\mathrm{SpO}_{2}$ and $\mathrm{HR}$ after ceasing PPV in preterm infants undergoing endotracheal intubation. AOT is shorter in preterm infants than that reported in older children and adults.

It is increasingly recognised that neonatal endotracheal intubation may be technically challenging, and clinical instability is common. The National Emergency Airway Registry for Neonates (NEAR4NEOS) recently reported a severe desaturation rate $\left(\geq 20 \%\right.$ decrease from baseline) of $48 \%$. $^{2}$ Adverse events were common during neonatal intubation, even in the relatively controlled setting of the NICU. $^{2}$ Adverse events are the most common cause of an intubation attempt being stopped in neonates. ${ }^{17}$ This results in some infants being exposed to multiple intubation attempts before the endotracheal tube is successfully placed. ${ }^{3}$ With an increasing number of intubation attempts, there is an increase in important complications including cardiac arrest, laryngospasm and air leak (pneumothorax and/or pneumomediastinum). ${ }^{18}$

Neonatal intubation is a mandatory skill for neonatal trainees, but one that is increasingly difficult to master and maintain, possibly due to increasing use of non-invasive ventilation and less-invasive surfactant administration techniques. ${ }^{19}$ To date, very little evidence is available to guide the optimal duration of an intubation attempt. Even when practitioners with considerable experience attempt intubation, many preterm infants are not intubated within the $30 \mathrm{~s}$ limit suggested by the Neonatal Resuscitation Program. ${ }^{717}$ This guideline does not distinguish between term and preterm infants. To our knowledge, no previous studies

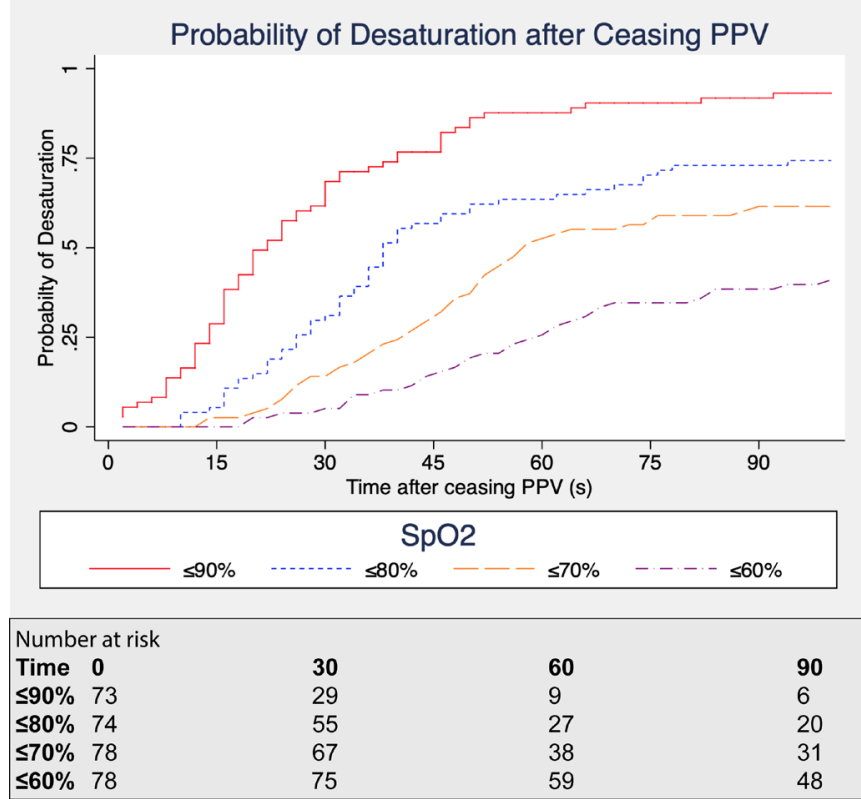

Figure 2 Kaplan-Meier probability curves of the probability of desaturation after ceasing PPV. PPV, positive pressure ventilation; $\mathrm{SpO}_{2^{\prime}}$ peripheral oxygen saturation; s, second.

have reported the AOT in preterm infants. Our data allows physiological targets to be correlated with time during intubation attempts. This study showed that the average AOT in preterm infants (time to desaturation $<90 \%$ ) was about $25 \mathrm{~s}$.

Similar to other studies, ${ }^{23520}$ we found a high rate of physiological instability in preterm infants during endotracheal intubation. The AOT in this trial was significantly shorter than values previously published by Patel and colleagues, ${ }^{12}$ reflecting the clinical impression that preterm infants become desaturated more rapidly than older infants and children. In contrast to older infants and children, preoxygenation is not universally applied in the neonatal population, due to concerns regarding potential adverse effects of hyperoxia, particularly in very preterm infants.

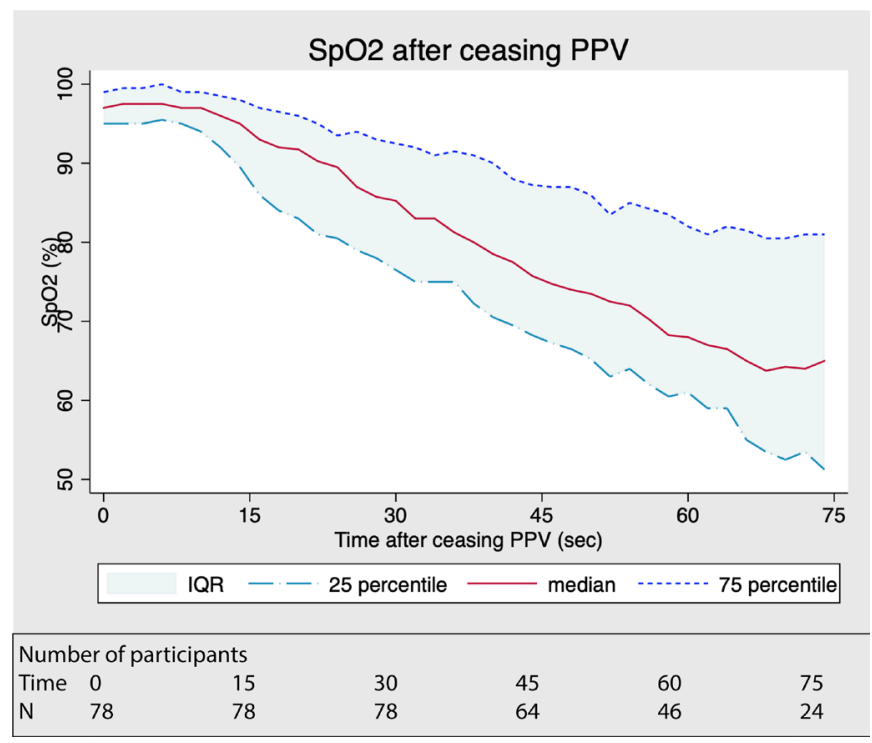

Figure 3 Change in peripheral oxygen saturation after ceasing PPV in premature infants undergoing elective intubation. PPV ceased at time 0. $\mathrm{PPV}$, positive pressure ventilation; $\mathrm{SpO}_{2}$, peripheral oxygen saturation. 
Previous studies have demonstrated that premedication before endotracheal intubation increases the speed of intubation and reduces the likelihood of associated adverse sequelae in infants. ${ }^{421-23}$ Krick et $a l^{24}$ showed that premedication with a muscle relaxant was associated with fewer intubation attempts, fewer adverse events and less bradycardia. In our study, the average HR decreased after ceasing PPV, but changes were minimal and not clinically important. There was no bradycardia, despite the observed severe desaturations, which might be explained by the routine administration of atropine.

Our study has several strengths. It provides insight into an important but underinvestigated issue in neonatal medicine. The detailed data collection enables an accurate measurement of AOT in neonates. We also acknowledge some limitations to our study. Some eligible neonates were not included in the analyses due to missing data. The accuracy of pulse oximeter data may not be maintained below lower saturation thresholds (eg, $\mathrm{SpO}_{2}$ $<70 \%)$.

This single site study was performed in a large perinatal centre and may not be generalisable to other settings, or to the DR, or to patients being intubated without premedication. There was a range of operator experience that may have influenced intubation success rates and therefore AOT. Furthermore, only very preterm infants undergoing elective endotracheal intubation in the neonatal unit were included; these data are not generalisable to apnoeic infants undergoing intubation in the DR, where functional residual capacity may not yet have been established.

In paediatric and adult populations, routine preoxygenation using $100 \%$ oxygen prior to endotracheal intubation may mitigate the risk of desaturation during the procedure. ${ }^{25}$ In neonates, the balance of potential adverse effects from hyperoxia and hypoxia should be considered. In line with local practice, infants in this study were not routinely preoxygenated, which may have influenced the time to desaturation.

Improving neonatal intubation safety requires consideration of multiple factors. This study was not powered to describe correlation between $\mathrm{SpO}_{2}$ or $\mathrm{HR}$ thresholds and clinical outcomes, but our data suggest that physiological stability criteria may be more appropriate than time-based criteria for intubation attempts. For some infants, especially if premedicated, this would allow for a more prolonged attempt, which might improve intubation success and reduce adverse events due to repeated intubation attempts. A randomised controlled trial showed that continuous delivery of transnasal high-flow humidified oxygen during apnoea significantly prolonged the AOT in older infants and children with healthy lungs. ${ }^{9}$ This is a topic that needs further research and is currently being studied in the neonatal population. ${ }^{26}$ Further research should also focus on other variables that may influence AOT in preterm infants, particularly the baseline clinical condition including preoxygenation, medications administered and physiological stability prior to the intubation attempt.

\section{CONCLUSION}

To our knowledge, this is the first study to report AOT in preterm infants. Desaturation occurs quickly after cessation of PPV and therefore the AOT is substantially shorter in preterm infants compared with paediatric patients. These data provide important clinical information for the development of clinical guidelines and studies to improve the safety of neonatal intubation.

Contributors RK was responsible for collection of data, analysis of data, drafting the manuscript and revising the final manuscript. EOC conceptualised and designed this current secondary analysis. $\mathrm{KAH}$ and EOC assisted with data collection. RK, KAH, BJM, MT, PGD and EOC participated in analysis and interpretation of data and revising of the manuscript. All authors approved the final version of the manuscript.

Funding National Health and Medical Research Council Centre for Research Excellence in Newborn Care (\#1153176) and National Health and Medical Research Council Program Grant (\#1113902).

Disclaimer The views expressed in the article are the authors own and are not an official position of the institution or funder. The authors have no financial relationships relevant to this article to disclose.

Competing interests None declared.

\section{Patient consent for publication Not required.}

Ethics approval The Royal Women's Hospital Research and Ethics Department approved the project in accordance with National Health and Medical Research Council guidelines (approval number 14/04) and the original trial was prospectively registered with the Australian New Zealand Clinical Trials Registry.

Provenance and peer review Not commissioned; externally peer reviewed.

Data availability statement All data relevant to the study are included in the article or uploaded as supplementary information. This was a secondary analysis of a randomised trial comparing two different facemask sizes used to deliver positive pressure ventilation to preterm infants prior to undergoing elective endotracheal intubation at The Royal Women's Hospital (RWH), Melbourne, Australia. As part of this randomised trial, video recordings of the endotracheal intubations were collected. Data for this study Data were recorded in a paper-based Case Record From then entered into an electronic database (REDCap)

Open access This is an open access article distributed in accordance with the Creative Commons Attribution Non Commercial (CC BY-NC 4.0) license, which permits others to distribute, remix, adapt, build upon this work non-commercially, and license their derivative works on different terms, provided the original work is properly cited, appropriate credit is given, any changes made indicated, and the use is non-commercial. See: http://creativecommons.org/licenses/by-nc/4.0/.

\section{ORCID iDs}

Radhika Kothari http://orcid.org/0000-0003-4782-2135

Kate Alison Hodgson http://orcid.org/0000-0003-3614-2388

Peter G Davis http://orcid.org/0000-0001-6742-7314

Eoin O'Currain http://orcid.org/0000-0002-9555-4561

\section{REFERENCES}

1 Hatch LD, Grubb PH, Lea AS, et al. Endotracheal intubation in neonates: a prospective study of adverse safety events in 162 infants. J Pediatr 2016;168:62-6.

2 Foglia EE, Ades A, Sawyer T. Neonatal intubation practice and outcomes: an international registry study. Pediatrics 2018:143.

3 Sawyer T, Foglia E, Hatch LD, et al. Improving neonatal intubation safety: a journey of a thousand miles. J Neonatal Perinatal Med 2017;10:125-31.

4 Marshall TA, Deeder R, Pai S, et al. Physiologic changes associated with endotracheal intubation in preterm infants. Crit Care Med 1984;12:501-3.

5 Foglia EE, Ades A, Napolitano N, et al. Factors associated with adverse events during tracheal intubation in the NICU. Neonatology 2015;108:23-9.

6 Haubner LY, Barry JS, Johnston LC, et al. Neonatal intubation performance: room for improvement in tertiary neonatal intensive care units. Resuscitation 2013;84:1359-64.

7 O'Donnell CPF, Kamlin COF, Davis PG, et al. Endotracheal intubation attempts during neonatal resuscitation: success rates, duration, and adverse effects. Pediatrics 2006:117:e16-21.

8 Weiner GM, Zaichkin J. Textbook of neonatal resuscitation (NRP). 7th edn, 2016: 326

9 Humphreys S, Lee-Archer P, Reyne G, et al. Transnasal humidified rapid-insufflation ventilatory exchange (thrive) in children: a randomized controlled trial. $\mathrm{Br} J$ Anaesth 2017;118:232-8

10 Lavizzari A, Veneroni $C$, Colnaghi $M$, et al. Respiratory mechanics during nCPAP and HHHFNC at equal distending pressures. Arch Dis Child Fetal Neonatal Ed 2014:99:315-20.

11 Kinouchi K, Tanigami H, Tashiro C, et al. Duration of apnea in anesthetized infants and children required for desaturation of hemoglobin to $95 \%$. The influence of upper respiratory infection. Anesthesiology 1992;77:1105-7.

12 Patel R, Lenczyk M, Hannallah RS, et al. Age and the onset of desaturation in apnoeic children. Can J Anaesth 1994;41:771-4.

13 O'Currain E, O'Shea JE, McGrory L, et al. Smaller facemasks for positive pressure ventilation in preterm infants: a randomised trial. Resuscitation 2019;134:91-8.

14 Motoyama EK, Glazener CH. Hypoxemia after general anesthesia in children. Anesth Analg 1986;65:267-72

15 Vijayakumar HR, Metriyakool K, Jewell MR. Effects of 100\% Oxygen and a Mixture of Oxygen and Air on Oxygen Saturation in the Immediate Postoperative Period in Children. Anesthesia \& Analgesia 1987;67:181-4. 


\section{Original research}

16 Harris PA, Taylor R, Thielke R, et al. Research electronic data capture (REDCap)-a metadata-driven methodology and workflow process for providing translational research informatics support. J Biomed Inform 2009;42:377-81.

17 O'Shea JE, Loganathan P, Thio M, et al. Analysis of unsuccessful Intubations in neonates using videolaryngoscopy recordings. Arch Dis Child Fetal Neonatal Ed 2018;103:F408-12.

18 Lee JH, Turner DA, Kamat $P$, et al. The number of tracheal intubation attempts matters! a prospective multi-institutional pediatric observational study. BMC Pediatr 2016;16:58.

19 O'Shea JE, O'Gorman J, Gupta A, et al. Orotracheal intubation in infants performed with a stylet versus without a stylet. Cochrane Database Syst Rev 2017;6:CD011791.

20 Hatch LD, Grubb PH, Lea AS, et al. Interventions to improve patient safety during intubation in the neonatal intensive care unit. Pediatrics 2016;138:138.

21 McAuliffe G, Bissonnette B, Boutin C. Should the routine use of atropine before succinylcholine in children be reconsidered? Can J Anaesth 1995;42:724-9.
22 Cook-Sather SD, Tulloch HV, Cnaan A, et al. A comparison of awake versus paralyzed tracheal intubation for infants with pyloric stenosis. Anesth Analg 1998:86:945-51.

23 Dempsey EM, Al Hazzani F, Faucher D, et al. Facilitation of neonatal endotracheal intubation with mivacurium and fentanyl in the neonatal intensive care unit. Arch Dis Child Fetal Neonatal Ed 2006;91:279-82.

24 Krick J, Gray M, Umoren R, et al. Premedication with paralysis improves intubation success and decreases adverse events in very low birth weight infants: a prospective cohort study. J Perinatol 2018;38:681-6.

25 Weingart SD, Levitan RM. Preoxygenation and prevention of desaturation during emergency airway management. Ann Emerg Med 2012;59:165-75.

26 Hodgson KA, Owen LS, Kamlin CO, et al. A multicentre, randomised trial of stabilisation with nasal high flow during neonatal endotracheal intubation (the shine trial): a study protocol. BMJ Open 2020;10:e039230. 